
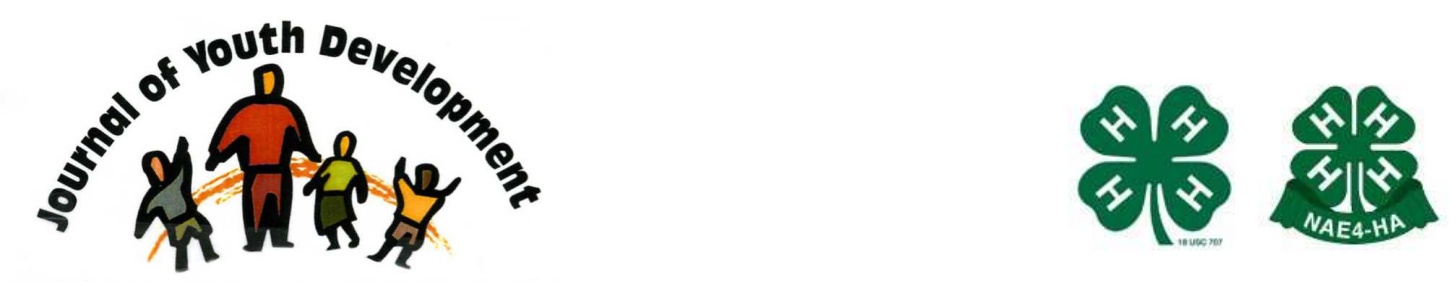

Bridging Research \& Practice

\title{
We're Here, We're Hopeful, and We Can Do Well: Conceptions and Attributes of Positive Youth Development among Immigrant Youth
}

\author{
Yulika Forman \\ Tufts University \\ Yulika.Forman@gmail.com \\ Dan Du \\ Tufts University \\ Dan.Du@tufts.edu \\ Megan Kiely \\ Tufts University \\ Megan.Kiely@tufts.edu \\ Jennifer Carrano \\ Boston College \\ Carranoj@bc.edu \\ Richard M. Lerner \\ Tufts University \\ richard.lerner@tufts.edu
}




\title{
JOURNAL OF YOUTH DEVELOPMENT \\ bridging research and practice

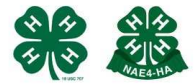

\section{We're Here, We're Hopeful, and We Can Do Well: Conceptions and Attributes of Positive Youth Development among Immigrant Youth}

\author{
Yulika Forman, Dan Du, Megan Kiely and Richard M. Lerner \\ Tufts University \\ Jennifer Carrano \\ Boston college
}

\begin{abstract}
Using qualitative and quantitative information from Grades 8 and 9 of the 4-H Study of Positive Youth Development (PYD), we describe the conceptions of thriving youth present within adolescent immigrants to the United States, and interrelate these conceptions with quantitative scores for PYD, contribution, and positive future orientation. Conceptions of thriving that included positive future orientation were associated with higher quantitative scores for PYD and Contribution. Conceiving of thriving as making contributions to themselves or their communities was associated with higher quantitative scores for Contribution. These findings suggest that immigrant youth whose qualitative definitions of thriving include the U.S.-based conceptions of PYD show quantitative evidence of positive functioning. We discuss limitations of the present study and directions for future research.
\end{abstract}

\section{Introduction}

Immigrants to any nation face multiple adaptive challenges, for instance, to adjust to their new national setting they need to understand what it means to do well, to succeed, or to thrive within the cultural context within which they now live. They need to understand, as well, how to build a positive future for themselves in their new country (Strohmeier \& SchmittRodermund, 2008). Arguably, these challenges may be especially complicated in adolescence, when adjustments also have to be made to changing physiological, cognitive, emotional, and social relational characteristics. How do adolescent immigrants fare in the face of their changing individual and contextual circumstances? We address this question by providing initial, descriptive information about characteristics of "positive youth development" (PYD) 
among adolescent immigrants in the United States (U.S.) and, as well, the links among PYD, youth contribution, and positive views of their future.

Since the early 1990s, the literature on adolescent development has shifted away from an emphasis on the deficits of youth, a perspective that maintained that young people are "problems to be managed" (Roth \& Brooks-Gunn, 2003) because of a biologically-based and universal tendency for storm and stress during this period of life (e.g., Erikson, 1968; Freud, 1969; Hall, 1904). Instead, and based in part on the potential for intraindividual plasticity (for systematic change in the structure and function of organismic and behavioral characteristics) across the adolescent period (Lerner, 2007), a strength-based conception of youth development has emerged, primarily through research within the United Stated (but see Silbereisen \& Lerner, 2007). Termed the PYD perspective, this conception specifies what successful development or thriving means, at least within a U.S. context, and emphasizes the possibility of positive development, or thriving, among allyouth. The key hypothesis within the PYD perspective is that such development occurs when the strengths of youth are aligned with resources for healthy development found in their homes, schools, and communities (Benson, Hamilton, Scales, \& Sesma, 2006; Damon, 2004; Lerner, 2004).

One of the key replicated findings within the PYD literature (Lerner, 2005) is that attributes of PYD - operationalized by "Five Cs," of competence, confidence, connection, character, and caring - exist in all U. S. youth who have been studied, and that PYD covaries positively within and across the adolescent years with youth contributions to self, family, and community (Jelicic, et al., 2007). In addition, youth with positive purposes or goals in life, and therefore with a positive orientation to their future, are also more likely to show higher PYD and Contribution scores (Gestsdottir \& Lerner, 2007; Zimmerman, et al., 2007). Lerner, et al. (2008) reported that youth with positive aspirations and expectations for their futures are most likely to show the highest levels of PYD across the early years of adolescence (i.e., Grades 5, 6, and 7). These relationships have been identified among adolescents of different races, ethnicities, socioeconomic levels, and places of residence (e.g., urban, rural, or suburban) within all geographic areas of the United States (e.g., Jelicic, et al., 2007; Lerner, et al., 2005; Phelps, et al., 2007; Theokas \& Lerner, 2006).

There has been, however, an important omission within this literature identifying the presence of attributes of PYD, and their links to "Contribution" and positive goals or future orientation among the diversity of American youth. Literature suggests that immigrant parents come to the United States with hopes for building a better future for their families and for their children's future success (Suarez-Orozco \& Suarez-Orozco, 2001). Children are often aware of the hopes placed on them by their parents and strive to justify the sacrifices their parents have made and continue to make on their behalf. However, to date, there has been no report of the extent to which samples of immigrant youth, in the United States or elsewhere, show evidence of these Five Cs or, as well, of the "sixth C," of contribution to self, others, or the community, that theory and research document develops among youth possessing high levels of PYD (e.g., Jelicic, et al., 2007). Similarly, researchers have not explored the extent to which a focus on the future, a notion integral to immigrant families, contributes to the positive development of immigrant youth.

Such a focus is important. There is considerable research documenting the risks and adjustment challenges facing immigrant youth (e.g., Fuligini, 1998; Sirin \& Fine, in press; Strohmeier \& Schmitt-Rodermund, 2008; Vazsonyi, Trejos-Castillo, \& Huang, 2006; Yu, Huang, Schwalberg, Overpeck, \& Kogan, 2003). Nevertheless, Suárez-Orozco, Todorova, and Qin 
(2006) note that relatively little attention has been paid to the psychological well-being of such youth, especially among adolescents who are immigrants within the United States. Given that the U.S. context defines thriving or positive development in terms associated with the PYD perspective (King, et al., 2005; Lerner, 2005, 2007), for immigrant youth to develop successfully during adolescence and into later life they need, as a foundation, an understanding of the conception of thriving present in their new setting. Therefore, we tested the expectation that, when immigrant youth maintain conceptions of a thriving youth that reflect ideas associated with the PYD perspective, they will in fact show evidence of positive functioning.

By using qualitative and quantitative information available within the longitudinal, 4-H Study of Positive Youth Development (Lerner, et al., 2005), we first describe, in their own words (Fine, Weis, Weseen, \& Wong, 2003), the conceptions of thriving, or positive development, presented by adolescents who are immigrants to the United States. We report the results of coding the responses of immigrant adolescents to open-ended questions about their conception of what it means to be a successful, thriving young person in order to determine whether their understanding of thriving includes terms related to conceptions present in the United States, that is, the Five Cs of PYD, Contribution, and a positive future orientation. We seek also to determine whether these conceptions include terms other than those linked to the PYD model. King, et al. (2005) assessed non-immigrant U.S. youth and found that both PYD and non-PYDrelated terms were used by adolescents when describing thriving. Finally, we explored whether there is any convergence between their qualitative responses and quantitative scores for PYD, Contribution, and expectations for a positive future.

Providing such preliminary descriptive information about immigrant youth is important for reasons of both theory and application. Given the purported higher levels of adjustment challenges among immigrant youth (e.g., see Strohmeier \& Schmitt-Rodermund, 2008, for reviews), one may question whether their development is marked also by the presence of PYD. Evidence that immigrant youth understand the terms of doing well in the U.S., that is, that their conception of thriving includes (in whole or in part) the conception of thriving extant in their new setting and, as well, that indicators of PYD, Contribution, and positive future orientation are related to these conceptions, would suggest that there is reason for adopting a strengthbased, PYD conception for the study of the individual and ecological bases of development among immigrant youth, in the same way that such a conception has been able to be adopted for racially and ethnically diverse groups of U.S. adolescents (Lerner, 2004).

As such, practitioners may more reasonably adopt a strength-based approach to enhancing the development of immigrant youth, despite the patterns of risks and problem behaviors they present (e.g., see Strohmeier \& Schmitt-Rodermund, 2008). Furthermore, examining the concept of thriving as described by immigrant youth in their own words provides an important opportunity to capture aspects of the concept that might be specific to this population.

In sum, in the present study we asked whether immigrant youth within the 4-H Study sample conceived of thriving in adolescence in terms consonant with the PYD perspective. As well, we assessed if their qualitative conceptions of thriving triangulated with quantitative data about PYD, Contribution, and expectations for a positive future.

\section{Method}

The 4-H Study was not designed as an investigation of immigrant youth. Nevertheless, as a consequence of the sampling approach used in the research (i.e., collecting data through 
schools in communities across the United States; see Lerner, et al., 2005, for details), immigrant youth became part of the sample. For the present study, youth in Grades 8 and 9 were combined and analyzed together in order to achieve a sufficient sample size. For youth present in both Grade 8 and Grade 9, their 9th Grade data were used.

The sample was thus $45 \%$ 8th-Graders and $55 \%$ 9th Graders. Data were obtained primarily from a Student Questionnaire (SQ). We also used demographic data collected from parents through a Parent Questionnaire (PQ) that was administered at all waves of data collection. Additional information about the 4-H Study method, including the development and psychometric characteristics of the measures, can be found in Gestsdottir \& Lerner (2007), Jelicic, et al. (2007), Lerner, et al. (2005), Theokas \& Lerner (2006), Zimmerman, et al. (2007). Below we present the features of methodology pertinent to the present report.

\section{Participants}

At Wave 4 of data collection, participants in the 4- $\mathrm{H}$ study came from sites located in 24 states that provided regional, rural-urban, racial/ethnic, and religious diversity. Participants were 1143 eighth grade adolescents $(39.5 \%$ males, mean age $=14.16$ years, $\mathrm{SD}=.57 ; 60.5 \%$ females, mean age $=14.07$ years, SD $=.54$ ) and 561 of their parents. At Wave 5 , participants came from sites located in 25 states that provided regional, rural-urban, racial/ethnic, and religious diversity. Participants were 1208 ninth grade adolescents $(41.3 \%$ males, mean age $=15.27$ years, $\mathrm{SD}=.57 ; 58.7 \%$ female, mean age $=15.08$ years, $S D=.48)$. The participants varied in regard to race, ethnicity, socioeconomic status, family structure, rural-urban location, geographic region, and experiences in after-school programs (Lerner, et al, 2005).

\section{The Immigrant Youth Sample}

To identify first and second generation immigrant youth, we used existing student and parent questionnaire items that assessed length of residence in the U.S. and use of foreign languages in various contexts. First generation immigrant participants were identified as those who have not lived in the U.S. their entire lives and spoke a language other than English in one of the following contexts: to themselves, with parents, or with siblings. Second generation immigrant youth were those individuals whose parents identified themselves as not having lived in the U.S. their entire lives and as speaking a language other than English in one of the following contexts: to themselves, at home, or with their children. Some of the adolescent immigrants identified through parent data were actually first generation immigrants, i.e. they immigrated into the U.S., just as their parents did. Participants who were second generation immigrants reported speaking a language other than English to themselves, their parents or their siblings. This approach, while possibly omitting some immigrant youth from our sample, provided the most assurance that our sample includes only immigrants rather than American citizens born overseas (i.e., we opted to err on the side of excluding "false negatives" rather than including "false positives").

This categorization process yielded 159 participants across Grades 8 and 9. From this group, we excluded participants who reported poor facility with written or spoken English. This process reduced the sample to a final $\mathrm{N}$ of 131 participants.

Accordingly, 131 immigrant youth (54\% girls; $45 \%$ 8th graders) varied with respect to race and ethnicity (European $=22.4 \%$, Latino/a $=43.2 \%$, Black $=15.2 \%$, Asian $=12.8 \%$, Multiethnic $/$ racial $=4.0 \%$, and Other $=2.4 \%$ ). Youth varied also in religious affiliation (Catholic $=$ $41.7 \%$, Protestant $=17.4 \%$, Muslim $=4.3 \%$, Hindu $=2.6 \%$, Other $=16.5 \%$; and None $=$ $16.5 \%)$. Most youth (82.4\%) were first-generation immigrants and the rest $(17.6 \%)$ were 
second-generation immigrants. The majority reported that they had lived in the United States for either five to nine years $(\mathrm{N}=50$, or $38.2 \%)$ or ten or more years $(\mathrm{N}=46$, or $35.1 \%)$. Twelve youth (9.2\%) reported having lived in the U.S. for one to four years and 23 secondgeneration immigrant respondents (17.6\%) reported that they had lived in the U.S. their entire lives.

Nearly half of the adolescents' parents (45.5\%) had attended college, whereas $39 \%$ completed high school and $15.6 \%$ had greater than a college-level education. Most youth $(57.9 \%)$ came from families with per capita incomes that fell between $0.0 \%$ to $99 \%$ of the federal poverty line, followed by families with incomes that fell between $100 \%$ to $199 \%$ percent of the federal poverty line $(23.7 \%)$, families with incomes between $200 \%$ to $299 \%$ percent of the federal poverty line (13.2\%), and families with incomes greater than or equal to $300 \%$ of the federal poverty line $(5.3 \%)$.

As a final check on whether these 131 youth were indeed immigrants, rather than children whose parents were in the military or on other out-of-the-country assignments, we assessed whether each child's reported ethnicity matched with the foreign language they reported speaking. An example of a match would be a respondent who reported being Asian American and speaking Chinese with his parents. For 121 (92\%) of the participants we were able to establish such a match. Self-reports of ethnicity for some participants in the 4-H sample change over time, and keeping in mind the multi-ethnic nature of many of the families in the sample, we believe that variation in ethic identification may be linked to a changing (developing) sense of self-identification among some youth. Accordingly, in light of such possible sources of variance in our data set, we were satisfied that the level of match we obtained indicated that our sampling procedures were accurate.

In regard to the languages spoken by the participants, the majority (62.6\%) spoke Spanish. In turn, $19.8 \%$ spoke Chinese, $5.3 \%$ spoke Vietnamese, 3.8\% spoke Creole, $3.1 \%$ spoke Russian, and $38.9 \%$ spoke other languages. The reason that the percentage of languages spoken exceeds $100 \%$ is that $30.5 \%$ of the participants spoke two foreign languages and $5.3 \%$ spoke three foreign languages.

\section{Procedure}

Participants were tested in groups within their schools (in more than $95 \%$ of the cases) or in after-school programs. Trained study staff or assistants, who began all testing sessions by reading the instructions to the participants, conducted data collection. Parent data were collected through teachers or program staff giving youth an envelope to take home to their parents. The envelope contained a letter explaining the study, consent forms for the child and his/her parent, a parent questionnaire, and a self-addressed envelope for returning the filled out forms and parent questionnaire.

\section{Qualitative Methods}

The SQ includes several open-ended items. One of these items was used to assess a youth's conception of a thriving young person: "Everybody has an idea about how she or he would like to be. If you imagine yourself doing really well in all areas of your life, what would you be like? What sorts of things would you do?" These questions were intended to assess the most salient concepts included in personal definitions of thriving, leaving the participants free to place their thoughts about thriving in the present or in the future. 
The qualitative analysis of the responses to this item was designed to assess if the youth used language consistent with the Five CS of PYD, Contribution, and positive future orientation. We assessed also if terms other than those involved with the PYD perspective (an admittedly U.S.derived conception; Lerner, 2004) were part of the immigrant adolescents' conceptions of a thriving youth.

Two sets of codes were used to provide these assessments; the final coding scheme is presented in Table 1. Based on the theoretical and empirical work of King, et al. (2005), who found that definitions of thriving by adults and youth could be organized according to the "Five Cs" of PYD, the first set of codes assessed the extent that descriptions of thriving used the terms associated with PYD, such as the "Five Cs," Contribution, and future orientation. Definitions of these codes were based on operationalizations provided through reference to the quantitative items indexing these concepts. Second, additional codes were generated from the data through open coding (i.e., identification of concepts within the data) (Strauss \& Corbin, 1998) to capture descriptions of thriving that were outside of the framework provided by the terms linked to the Five Cs and Contribution. Definitions of these codes were developed by the authors to ensure consistency in coding. Answers such as "I don't know," nonsensical sentences, such as "It well [sic] not have no bad people there," and sentences that were general and vague or did not contain information relevant to the question were considered uncodable. Finally, we used the responses also to assess also whether immigrant youth demonstrated in their conceptions of a thriving young person a positive orientation to the future.

A codebook was developed by three raters based on the data in the first three waves of data (Grades 5, 6, and 7) in the 4-H Study (e.g., Phelps, et al., 2007). In order to determine intercoder reliability, two of the raters used this codebook to independently code an additional 100 cases. There was a high rate of agreement between the two raters as indicated by Cohen's kappa, $k=.83$. Given this consistency, the immigrant youth cases were coded by one of the coders. 
Table 1

Coding categories and response percentages to questions about the characteristics of a thriving youth among immigrant youth, $\mathrm{N}=102$

\begin{tabular}{|c|c|}
\hline Category & Percentage of Responses \\
\hline \multicolumn{2}{|c|}{ Theoretically-based Codes } \\
\hline Competence & 22.6 \\
\hline Connection & 7.8 \\
\hline Confidence & 2 \\
\hline Character & 1 \\
\hline Caring & 1 \\
\hline Contribution & 29.4 \\
\hline Future & 52.9 \\
\hline Future: Job/Occupation & 44.1 \\
\hline Future: Family & 8.8 \\
\hline Future: Financial well-being & 8.8 \\
\hline Future: Other & 8.8 \\
\hline Future: Education & 6.9 \\
\hline \multicolumn{2}{|c|}{ Codes Derived from the Data } \\
\hline $\begin{array}{l}\text { Emotion, Personal Characteristic, } \\
\text { Behavior/Conduct }\end{array}$ & 21.6 \\
\hline Activity/Interest & 18.6 \\
\hline Agency/Independence & 8.8 \\
\hline Being Perfect & 4.9 \\
\hline Challenging the Concept of Thriving & 3.9 \\
\hline
\end{tabular}

\section{Quantitative Methods}

As described by Lerner, et al. (2005; also see Theokas \& Lerner, 2006), the 4-H data set contains a large set of measures of demographic, individual/behavioral, social relational, familial, and community variables. From this larger set, the following measures were used in the quantitative analyses:

- The Five Cs of PYD and Contribution. The Five Cs of PYD - Competence, Confidence, Connection, Character, and Caring - and, as well the "6th C," of Contribution - are measured in the SQ from items derived from four measures: the Profiles of Student Life-Attitudes and Behaviors Survey (PSL-AB) (Benson, Leffert, Scales, \& Blyth, 1998), the Self-Perception Profile for Children (SPPC; Harter, 1983), the Peer Support Scale (Armsden \& Greenberger, 1987) from the Teen Assessment Project 
Survey Question Bank (Small \& Rodgers, 1995), and the Eisenberg Sympathy Scale (Eisenberg et al., 1996). As explained in prior publications, which include the details of measure construction and psychometric information, PYD is constructed as the mean of the Five Cs (Jelicic, et al., 2007; Lerner, et al., 2005; Phelps, et al., 2007). Contribution is measured as a total score (derived from 12 items within the SQ).

- Positive Future. An index for positive future (Cronbach's alpha $=.96$ ) was created from 10 SQ items that assessed the likelihood positive events would be part of their future. These items were: Have a job that pays well; have a job they like; have a happy family life; be able to live wherever they want; be able to buy the things they want; be able to do the things they want; be respected in the community; have friends they can count on; be healthy; and be safe. All items had a five-point rating scale, ranging from $1=$ Very low to $5=$ Very high. A composite score was computed as the mean score across items. However, due to a high negative skew in the distribution of these scores (mean $=4.14$ ), a dichotomous variable was created for further analysis. Youth with scores below 4 were coded as $0=$ lower positive future expectations, and youth with scores greater than or equal to 4 were coded as $1=$ higher positive future expectations.

\section{Results}

The purpose of the study was to determine if immigrant adolescent youth had conceptions of a thriving young person that included terms consonant with the concepts involved in the PYD perspective (Damon, 2004; Lerner, 2005, 2007), such as the Five Cs, Contribution, and a positive future orientation. The PYD perspective is a largely U.S.-based conception (Lerner, 2004), and so we sought to assess also if immigrant youth used terms other than those associated with this perspective when discussing their conception of a thriving young person.

Finally, in order to test the expectation that immigrant youth who conceived of thriving in terms consonant with the PYD perspective would show more evidence of positive development than youth who did not have this conception, we assessed the convergence between this qualitatively-derived information about immigrant youth and their quantitative scores for the PYD concepts measured within the 4-H Study data set. We organize our results around the information we obtained in regard to these goals of the research.

\section{Immigrant Youth Conceptions of a Thriving Young Person}

To identify the terms immigrant youth use to convey their conception of a thriving young person, we coded responses to the questions, "Everybody has an idea about how she or he would like to be. If you imagine yourself doing really well in all areas of your life, what would you be like? What sorts of things would you do?" Of the 131 youth included in our sample, 21 $(16 \%)$ did not answer this question, and $8(6 \%)$ gave uncodable answers. Therefore, 102 youth provided codable answers and the analyses below are based on the data from those participants.

Eighty-six (65.6\%) of these participants used language consistent with the terminology of PYD in their definitions of thriving. As shown in Table 1, of the Five Cs, Competence was mentioned most often (by 22.6\%) and Caring and Character least often (by $1 \%$ in both cases). In turn, Contribution was mentioned by $29.4 \%$ of the youth. Moreover, a majority of the youth (52.9\%) included in their conceptions of thriving ideas about a positive future, for instance, regarding desirable outcomes such as having a job or a family and financial success. 
Examples of some of the statements youth made about Competence included being a good student, being smart, and being good at sports or other activities. For example, one participant wrote, "I'd be top of my class and win all my rodeo contests." Another one stated, "I would get all A's at school. Become a better Artist...."

Most of the participants discussed contribution in general terms, such as "helping others," helping some people," "helping out," or "being "helpful." Some participants, however, wrote about specific causes they would contribute to, or specific ways in which they would like to help. For example, one respondent wrote, "I would be in Mexico helping out my people by giving them food and shelter." Another one stated, "I would like to be a doctor to help the people in Mauritania." Some participants wrote about "contribution to self" (Lerner, 2004), i.e. their answers reflected their understanding that taking care of oneself is an important responsibility. For example, one participant said that he would "have a great amount of energy to exercise a lot (not being lazy)." Another one noted that she "...would have good life, and I would do what's good for me and help some people."

In regard to statements about a positive future, many youth described their idealized futures as having a college education, a job, a family, or financial success. For example, one participant stated, "I would first of all go through medical school as I planned. I see myself as a surgeon in Ireland." Another participant wrote, "Well I would be a top-class attorney fighting for people's rights and live in an expensive apt. in downtown Boston," while another one wrote, "I would be rich and help Animal Shelters every where in Arizona." As exemplified by the latter two quotes, for many respondents financial success was tied in with the ability to make a contribution, i.e. with being able to use their imagined future success to help their families, communities, or other causes.

However, $42(32.1 \%)$ of the immigrant youth did not restrict themselves to the use of terms embodied within the PYD perspective. One salient additional theme included in participants' conceptions of a thriving youth was positive personal characteristics, emotions or behaviors. These topics were found in the statements of $21.6 \%$ of the youth. For example, referring to themselves, participants wrote that they would "change my behavior," "do harder and challenging things," and "not lose my temper so much." In addition, the participants discussed such concepts as being a "good" or "perfect" person, and being "happy" and "social." King, et al. (2005) also reported that U.S. youth respond to questions about the meaning of thriving by using terms that fall outside of the frame provided by the PYD perspective. The terms found within the present sample correspond to those reported as well by King, et al.

Interestingly, a small number of participants (3.92\% of the sample) questioned the value of doing well in all areas of their lives either as impossibility, or as a situation that would not be beneficial for them. For example, one participant wrote, "Well if I was doing well in all areas of my life then I guess this world would be perfect no? So basically I can't even begin to imagine that for it would never happen so why waste time on even trying to?" Another participant stated, "I don't feel that I would be as mature as I am now. I have gotten where I am today by learning from my mistakes and failures, and have gained a sense of appreciation for the areas in my life that I am good at."

Correspondence between Immigrant Youth Conceptions of a Thriving Young Person and Quantitative Scores for PYD-related Variables 
To better understand whether the conceptions of immigrant youth that included ideas pertinent to the PYD perspective indicated anything about the status of their positive development, we interrelated information about their statements regarding thriving youth with their quantitative scores for PYD (mean $=69.0, S D=13.2$ ), Contribution (mean $=47.5, S D=15.5$ ), and positive future $($ mean $=4.1, S D=0.8)$.

Immigrant youth whose conceptions of thriving included a future orientation had significantly higher scores on PYD, $t(124)=4.919, p<.001$ and Contribution, $t(121)=4.005, p<.001$, compared with youth who did not include a future orientation. However, there were no significant differences between these youth in terms of their quantitative scores for positive future.

In turn, youth whose conceptions of a thriving young included Contribution had significantly higher quantitative Contribution scores, $t(121)=2.431, p<.05$, than did youth who did not discuss Contribution in their definitions of thriving. However, adolescent immigrants whose definitions of thriving included at least one of the Five Cs did not differ from adolescents who did not discuss any of the Five Cs in regard to their quantitative PYD scores.

In short, conceptions of a thriving youth that included ideas about a positive future were associated with higher quantitative scores for both PYD and Contribution. In addition, conceiving of thriving youth as making contributions to their selves or their communities was associated with higher quantitative scores for Contribution. Thus, there is evidence from these analyses that immigrant youth whose understanding of thriving includes PYD show evidence of positive functioning during their adolescent years.

\section{Discussion}

Immigrant adolescents face challenges associated with both adjusting to the individual and social transitions of their age period and, as well, challenges of adapting to their new national context while maintaining a connection to their cultures of origin (Suarez-Orozco, \& SuarezOrozco, 2001). This study provides initial descriptive information about how adolescent immigrants are faring in regard to their changing individual and contextual circumstances through using the conceptual lens provided by the "positive youth development" (PYD) perspective (Damon, 2004; Lerner, 2005, 2007). Using data from the 4-H Study of PYD (Lerner, et al., 2005), we found that immigrant adolescent youth had conceptions of a thriving young person that included terms consonant with the concepts involved in the PYD perspective (Damon, 2004; Lerner, 2005, 2007), such as the Five Cs, Contribution, and a positive future orientation, as well as other terms not linked to these ideas.

However, in that the PYD perspective is a largely U.S.-based conception (Lerner, 2004), we argued that immigrant youth use of terms associated with this conception when describing what they believed a thriving young person to be might be an indication that they have adjusted well to their new national context. Of course, it is also possible that the conception of thriving in their culture of origin might be at least to some extent aligned with the U.S.-based definition of thriving. However, giving the paucity of PYD research that has been published in other than U.S. settings (see Silbereisen \& Lerner, 2007), this possibility cannot be tested at this writing.

Accordingly, we explored whether qualitative conceptions of a thriving young person among immigrant adolescent youth covaried with quantitative scores indicative of positive youth development and contribution. Our analyses of the convergence between the qualitative and 
quantitative data were used to address this issue and provided evidence that immigrant youth who include in their conception of thriving (in whole or in part) the ideas associated with the PYD perspective (the Five Cs, Contribution, and positive future orientation), had higher quantitative scores for both PYD and Contribution. Given the well-documented future orientation of immigrant youth (Suarez-Orozco \& Suarez-Orozco, 2001), immigrant adolescents may possess an important strength in their potential for positive development. These data provide preliminary empirical reason for adopting a strength-based, PYD framework for studying the individual and ecological bases of development among immigrant youth. In addition, our findings provide a rationale for practitioners to develop programs based on a strength-based approach to enhancing the development of immigrant youth.

Of course, these implications are constrained by the limitations of the present study. The 4-H Study was not designed to be a study of immigrant youth, and therefore our sample was gathered in an ad hoc manner instead of intentionally. Due to the above limitations, we were not able to consider the length of residence in the U.S., acculturation (Motti-Stefanidi, Pavlopoulos, Obradovic, \& Masten, 2008; Oppedal, Roysamb, \& Sam, 2004), and other factors relevant to the positive development of immigrant populations in our research. Considering immigrant adolescents coming from various countries (Lien, Dalgard, Heyerdahl, Thoresen, \& Bjertness, 2006; Pong, Hao, \& Gardner, 2005) and belonging to first and second generation (Driscoll, Russell, \& Crockett, 2008; Harker, 2001; Portes \& Rumbaut, 2005) as a combined, homogenous group presents another limitation of this study.

In addition, our results are limited by the definitions of immigrant status we employed and by the particular qualitative and quantitative indices included in our measurement model. For example, these limitations precluded investigation of important nuances and possible negative cases (Denzin \& Lincoln, 2003) in our findings, such as a more in-depth look at youth who challenged the concept of thriving. As well, the definitions of thriving provided by the participants may not be complete, as we were not able to probe for additional relevant concepts and meanings. Nevertheless, we consider their answers to be indicative of the most salient concepts included in personal definitions of thriving. In addition, it is reasonable to question the extent to which immigrant youth are able to express their thoughts in what may be for many participants their second language. To address this concern, we included in the analyses only those youth who indicated that they knew English well or very well. Furthermore, both of our coders were European American and their understanding of participants' written responses might have been limited by their cultural biases.

Moreover, in that the information we extracted from the longitudinal data set was crosssectional information about eighth and ninth grade youth, our findings cannot be generalized to other adolescent age groups or across ontogenetic time. Nevertheless, in that the 4-H Study is a longitudinal investigation, this latter limitation can be addressed in future analyses of the present data set.

Future research should assess not only larger and more intentionally gathered groups of youth who are immigrants to the U.S. but, as well, should assess youth immigrants in other nations, especially because of the contemporary social, economic, and social justice issues challenging their healthy development (Strohmeier \& Schmitt-Rodermund, 2008). Such research would also be valuable if it assessed whether the PYD perspective generalizes to national settings other than the U.S. Such cross-national comparisons are only beginning (e.g., Silbereisen \& Lerner, 2007), but it may be that there are important interactions between particular ethnic, racial, and religious immigrant groups in particular nations that make conceptions of PYD and their 
implications for thriving different across groups. In addition, along with studies using quantitative approaches, in-depth qualitative studies are needed that would provide rich and contextualized descriptions (Denzin \& Lincoln, 2003) of culture-specific, as well as universal, aspects of conceptions of thriving and their relationship to quantitative indicators of PYD in both in the Western and non-Western world.

The present data are neither powerful enough nor sufficiently nuanced to elucidate these possibilities. Nevertheless, the findings we have presented do suggest that, in trying to depict the status of positive development among immigrant adolescents, there is merit in asking whether their conceptions of thriving youth correspond to ideas about such development within their new nations of residence.

\section{References}

Armsden, G., \& Greenberg, M. (1987). The Inventory of Parent and Peer Attachment: Individual differences and their relationship to psychological well-being in adolescence. Journal of Youth and Adolescence, 16, 427-454.

Benson, P.L., Leffert, N., Scales, P.C., \& Blyth, D.A. (1998). Beyond the 'village' rhetoric: creating healthy communities for children and adolescents. Applied Developmental Science, 2(3), 138-159.

Benson, P.L., Scales, P.C., Hamilton, S.F., \& Sesma, A., Jr. (2006). Positive youth development: Theory, research, and applications. In R.M. Lerner (Ed.). Theoretical models of human development. Volume 1 of Handbook of Child Psychology (6th ed.) (pp. 894-941). Editors-inchief: W. Damon \& R. M. Lerner. Hoboken, NJ: Wiley.

Damon, W. (2004). What is positive youth development? The Annals of the American Academy of Political and Social Science, 591, 13-24.

Denzin, N.K., \& Lincoln, Y.S. (2003). Introduction: The history and practice of qualitative research. In N. K. Denzin \& Y. S. Lincoln (Eds.). The landscape of qualitative research: Theories and Issues, (pp. 1-46). Sage Publications.

Driscoll, A.K., Russell, S.T., \& Crockett, L.J. (2008). Parenting styles and youth well-being across immigrant generations. Journal of Family Issues, 29, 185-209.

Eisenberg, N., Fabes, R.A., Murphy, B.C., Karbon, M., Smith, M., \& Maszk, P. (1996). The relations of children's dispositional empathy-related responding to their emotionality, regulation, and social functioning. Developmental Psychology, 32, 195-209.

Erikson, E.H. (1968). Identity, youth, and crisis. New York: Norton.

Fine, M., Weis, L., Weseen, S., \& Wong, L. (2003). For whom? Qualitative research, representations and social responsibilities. In N. K. Denzin, \& Y. S. Lincoln (Eds.) The landscape of qualitative research: Theories and Issues, (pp. 167-207). Sage Publications.

Freud, A. (1969). Adolescence as a developmental disturbance. In G. Caplan \& S. Lebovici (Eds.), Adolescence (pp.5-10). New York: Basic Books. 
Fuligni, A.J. (1998). The adjustment of children from immigrant families. Current Directions in Psychological Science, 7(4), 99-103.

Gestsdottir, S., \& Lerner, R.M. (2007). Intentional self-regulation and positive youth development in early adolescence: Findings from the 4-H Study of Positive Youth Development. Developmental Psychology, 43(2), 508-521.

Hall, G.S. (1904). Adolescence: Its psychology and its relations to psychology. anthropology, sociology, sex, crime, religion, and education. New York: Appleton.

Harker, K. (2001) Immigrant generation, assimilation and adolescent psychological well-being. Social Forces, 79, 969-1004.

Harter, S. (1983). Developmental perspectives on the self-system. In P. Mussen \& E. M. Hetherington (Eds.), Handbook of child psychology: Vol. 4. Socialization, personality, and social development (4th ed., pp. 275-385). New York: Wiley.

Jelicic, H., Bobek, D., Phelps, E., Lerner, J.V., \& Lerner, R.M. (2007). Using positive youth development to predict contribution and risk behaviors in early adolescence: Findings from the first two waves of the 4-H Study of Positive Youth Development. International Journal of Behavioral Development, 31(3), 263-273.

King, P.E., Dowling, E.M., Mueller, R.A., White, K., Schultz, W., \& Osborn, P., et al. (2005). Thriving in Adolescence: The voices of youth-serving practitioners, parents, and early and late adolescents. Journal of Early Adolescence, 25(1), 94-112.

Lien, L., Dalgard, F., Heyerdahl, S., Thoresen, M., \& Bjertness, E. (2006). The relationship between age of menarche and mental distress in Norwegian adolescent girls and girls from different immigrant groups in Norway: Results from an urban city cross-sectional survey. Social Science \& Medicine, 63, 285-295.

Lerner, R.M. (2004). Liberty: Thriving and civic engagement among America's youth. Thousand Oaks, CA: Sage Publications.

Lerner, R.M. (2005, September). Promoting Positive Youth Development: Theoretical and Empirical Bases. White paper prepared for the Workshop on the Science of Adolescent Health and Development, National Research Council/Institute of Medicine. Washington, D.C.: National Academies of Science.

Lerner, R.M. (2007). The Good Teen: Rescuing Adolescents from the Myths of the Storm and Stress Years. New York, NY: The Crown Publishing Group.

Lerner, R.M., Lerner, J.V., Almerigi, J., Theokas, C., Phelps, E., \& Gestsdottir, S., et al. (2005). Positive youth development, participation in community youth development programs, and community contributions of fifth grade adolescents: Findings from the first wave of the 4-H Study of Positive Youth Development. Journal of Early Adolescence, 25(1), 17-71. 
Lerner, R.M., Lerner, J.V., Phelps, E., \& Colleagues at the Institute for Applied Research in Youth Development. (2008). The 4-H Study of Positive Youth Development: Report on the findings from the first four waves of data collection: 2002-2006. Medford, MA: Author.

Motti-Stefanidi, F., Pavlopoulos, V., Obradovic, J., \& Masten, A.S. (2008). Acculturation and adaptation of immigrant adolescents in Greek urban schools. International Journal of Psychology, 43, 45-58.

Oppedal, B., Roysamb, E., \& Sam, D.L. (2004). The effect of acculturation and social support on change in mental health among young immigrants. International Journal of Behavioral Development, 28, 481-494.

Phelps, E., Balsano, A., Fay, K., Peltz, J., Zimmerman, S., Lerner, R.M., \& Lerner, J.V. (2007). Nuances in early adolescent development trajectories of positive and of problematic/risk behaviors: Findings from the 4-H Study of Positive Youth Development. Child and Adolescent Clinics of North America, 16(2), 473-496.

Pong, S., Hao, L., \& Gardner, E. (2005). The roles of parenting styles and social capital in the school performance of immigrant Asian and Hispanic adolescents. Social Science Quarterly, 86, 928-950.

Portes, A., \& Rumbaut, R.G. (2005) Introduction: The Second Generation and the Children of Immigrants Longitudinal Study. Ethnic and Racial Studies, 28, 983-999.

Roth, J.L., \& Brooks-Gunn, J. (2003). What is a youth development program? Identification and defining principles. In F. Jacobs, D. Wertlieb, \& R.M. Lerner (Eds.), Enhancing the life chances of youth and families: Public service systems and public policy perspectives: Vol. 2 Handbook of applied developmental science: Promoting positive child, adolescent, and family development through research, policies, and programs (pp. 197-223). Thousand Oaks, CA: Sage.

Silbereisen, R.K., \& Lerner, R.M. (Eds.). (2007). Approaches to positive youth development. London: Sage Publications.

Sirin, S., \& Fine, M. (In press). Designated Others: Muslim American Youth Negotiating their Identities Post 9-11. New York: New York University Press.

Small, S.A., \& Rodgers, K.B. (1995). Teen Assessment Project (TAP) Survey Question Bank. Madison: University of Wisconsin-Madison.

Strauss, A., \& Corbin, J. (1998). Basics of qualitative research: Techniques and procedures for developing grounded theory (2nd ed.). Thousand Oaks, CA: Sage.

Strohmeier, D., \& Schmitt-Rodermund, E. (Eds.). (2008). Immigrant youth in European countries. European Journal of Developmental Psychology, 5(2).

Suarez-Orozco, C., \& Suarez-Orozco, M. (2001). Children of immigration. Cambridge, MA: Harvard University Press.

Suarez-Orozco, C., Todorova, I.L.G., \& Qin, D.B. (2006). The well-being of immigrant adolescents: A longitudinal perspective on risk and protective factors. In F. A. Villarruel, \& T. 
Luster (Eds.), The crisis in youth mental health: Critical issues and effective programs, Vol. 2: Disorders in adolescence, (pp. 53-83). Westport, CT: Praeger Publishers/Greenwood Publishing Group.

Theokas, C., \& Lerner, R.M. (2006). Observed Ecological Assets in Families, Schools, and Neighborhoods: Conceptualization, Measurement and Relations with Positive and Negative Developmental Outcomes. Applied Developmental Science, 10(2), 61-74.

Vazsonyi, A.T., Trejos-Castillo, E., \& Huang, L. (2006). Are developmental processes affected by immigration? Family processes, internalizing behaviors, and externalizing behaviors. Journal of Youth and Adolescence, 35(5), 799-813.

Yu, S.M., Huang, Z.J., Schwalbger, R.H., Overpeck, M., \& Kogan, M.D. (2003). Acculturation and the health and well-being of U.S. immigrant adolescents. Journal of Adolescent Health, $33(6), 479-488$.

Zimmerman, S., Phelps, E., \& Lerner, R.M. (2007). Intentional self-regulation in early adolescence: Assessing the structure of selection, optimization, and compensations processes. European Journal of Developmental Science, 1(3), 272-299.

(C) Copyright of Journal of Youth Development $~$ Bridging Research and Practice. Content may not be copied or emailed to multiple sites or posted to a listserv without copyright holder's express written permission. However, users may print, download or email articles for individual use. 